\title{
Detection of diabetic macular oedema: validation of optical coherence tomography using both foveal thickness and intraretinal fluid
}

Carmen Hernández-Martínez, Antonio Palazón-Bru, Cesar Azrak, Aída Navarro-Navarro, Manuel V Baeza-Díaz, Jose J MartínezToldos, Vicente F Gil-Guillén

No studies have yet evaluated jointly central foveal thickness (CVT) and the presence of intraretinal fluid (PIF) to diagnose diabetic macular oedema (DMO) using optic coherence tomography (OCT). We performed a cross-sectional observational study to validate OCT for the diagnosis of DMO using both CVT and PIF assessed by OCT (3D OCT-1 Maestro). A sample of 277 eyes from primary care diabetic patients was assessed in a Spanish region in 2014. Outcome: DMO diagnosed by stereoscopic mydriatic fundoscopy. OCT was used to measure CVT and PIF. A binary logistic regression model was constructed to predict the outcome using CVT and PIF. The area under the ROC curve (AUC) of the model was calculated and non-linear equations used to determine which CVT values had a high probability of the outcome (positive test), distinguishing between the presence or absence of PIF. Calculations were made of the sensitivity, specificity, and the positive (PLR) and negative (NLR) likelihood ratios. The model was validated using bootstrapping methodology. A total of 37 eyes had DMO. AUC: 0.88 . Positive test: CVT $\geq 90 \mu \mathrm{m}$ plus PIF ( $\geq 310 \mu \mathrm{m}$ if no PIF). Clinical parameters: sensitivity, 0.83; specificity, 0.89; PLR, 7.34; NLR, 0.19 . The parameters in the validation were similar. In conclusion, combining PIF and CVT provided a tool to very precisely discriminate the presence of DMO. Similar studies are needed to provide greater scientific evidence for the use of PIF in the diagnosis of DMO. 
1 Authors: Carmen Hernández-Martínez [1], Antonio Palazón-Bru [2,3], Cesar Azrak [1], Aida

2 Navarro-Navarro [1], Manuel Vicente Baeza-Díaz [1], José Juan Martínez-Toldos [1], Vicente

3 Francisco Gil-Guillén [2,3].

4 Institutions:

5 1. Ophthalmology Service, General Hospital of Elche, Elche, Alicante, Spain.

6 2. Department of Clinical Medicine, Miguel Hernández University, San Juan de Alicante,

7 Alicante, Spain.

8 3. Research Unit, Elda Hospital, Elda, Alicante, Spain.

9 Corresponding author: Prof. Antonio Palazón-Bru, PhD, Department of Clinical Medicine,

10 Miguel Hernández University, San Juan de Alicante, Spain. E-mail: antonio.pb23@gmail.com.

11 Phone: +34 965919449. Fax: +34 965919450.

12 
INTRODUCTION

14 Diabetes mellitus affects around 180 million people worldwide (WHO, 2002). Two important

15 complications of the disease result in loss of vision, proliferative diabetic retinopathy and

16 diabetic macular oedema. The latter is the leading cause of reduced vision in diabetic patients

17 (No authors listed, 1987; Aiello, 2003).

The diagnostic method of reference (Clinical Standard) for diabetic macular oedema is based on the stereoscopic examination of the fundus of the eye using a magnifying lens (with or without making contact) to visualise the retina with mydriasis (No authors listed, 1985; Kinyoun et al., 1989). Other methods, more common in primary care, are direct ophthalmoscopy or nonstereoscopic retinography. However, diffuse thickening or thickening in the form of retinal cysts as the initial sign of diabetic macular oedema may go unnoticed with these examination methods, as they can only detect macular oedema from the presence of hard exudates or indirect signs, such as macular haemorrhage or microaneurysms (Aldington et al., 1995; Bursell et al., 2001;

Gómez-Ulla et al., 2002; Rudinsky et al., 2002; Herbert, Jordan \& Flanagan, 2003; Baeza Diaz et al., 2004; Baeza et al., 2009).

The introduction of optical coherence tomography (OCT) led to changes in both the diagnosis and the management of diabetic macular oedema. OCT can provide high-resolution cross-sectional images of the retina. These can give us information about the retinal thickness and its morphology, as well as whether or not there is intraretinal fluid, key information in the diagnosis of diabetic macular oedema (Hee et al., 1995; Hee et al., 1996; Koozekanani et al.,

33 2000; Browning et al., 2004; Virgili et al., 2015). 
Some OCT devices can provide an image of the retina as well as a cross-sectional view.

35 These two observations constitute an excellent tool for the diagnosis of macular oedema.

Accordingly, the use of OCT can be considered as a screening method for diabetic macular

oedema in primary care, given that it solves the problems associated with the previously

described methods. However, as studies assessing the validity of OCT as a diagnostic method for macular oedema are lacking, we undertook a study to validate OCT (3D OCT-1 Maestro; Topcon Corporation ${ }^{\circledR}$, Itabashi, Tokyo, Japan) for the diagnosis of diabetic macular oedema.

\section{MATERIALS \& METHODS}

\section{Study population}

Diabetic patients who attended their primary healthcare centre in Elche (Spain), an industrial city with a medium socioeconomic status.

\section{Study design and participants}

47 This cross-sectional observational study involved a sample of diabetic patients (types 1 and 2) who attended their primary healthcare centres (in the General Hospital of Elche catchment area) between January and May 2014 for screening for diabetic retinopathy and diabetic macular oedema. Exclusion criteria were at least one of the following: another macular disorder, high myopia, dementia, a cataract operation during the previous three months, vitreoretinal surgery,

52 laser treatment in the macular area or panphotocoagulation, and anti-angiogenic drugs.

\section{Variables and measurements}


54 The main study outcome variable was the presence of diabetic macular oedema, determined by

55 stereoscopic mydriatic fundoscopy using a slit lamp with a non-contact magnifying lens (78D

56 aspheric lens. Volk Optical Incorporated Company; Mentor, OH), performed by an expert retinal

57 ophthalmologist (No authors listed, 1985; Kinyoun et al., 1989).

Using the OCT that we wished to validate, we obtained information about the central foveal thickness $(\mu \mathrm{m})$ and the presence of intraretinal fluid or cysts (hyporeflective areas). The

60 central foveal thickness was obtained after dilation of the pupil with a drop of tropicamide. The

61 images were acquired as a 3D $6 \mathrm{~mm} \times 6 \mathrm{~mm}$ volume cube. The mean retinal thickness was

62 calculated automatically by the device software. This was used to evaluate the central circle

$63(1000 \mu \mathrm{m}$ in diameter). In addition, we used the OCT to obtain a horizontal tomographic image

64 of the retina (B-Scan), in which we assessed the presence or otherwise of intraretinal fluid (cysts 65 or hyporeflective intraretinal areas) (Fig. 1). dyslipidaemia, smoking, age (years), years since diagnosis of diabetes, body mass index (BMI)

$69\left(\mathrm{~kg} / \mathrm{m}^{2}\right), \mathrm{HbAlc}(\%)$ and best corrected visual acuity. These variables were determined from a clinical interview and corroborated by the charts, except for BMI, HbAlc and visual acuity, 71 which were measured using standard methods (American Diabetes Association, 2014).

\section{Sample size}

The final sample comprised 277 eyes, of which 37 showed diabetic macular oedema. In order to contrast an area under the ROC curve (AUC) different from 0.5 (the tested variable does not have the discriminatory power to identify diabetic macular oedema in the patients), assuming 
$95 \%$ confidence and an expected AUC of 0.85 , the statistical power obtained was almost $100 \%$ (Hanley \& McNeil, 1982).

\section{Statistical methods}

The variables are described as absolute and relative frequencies (qualitative variables) or means and standard deviations (quantitative variables). A binary logistic regression model using generalized estimating equations (to take into account that we could have two values in the data set for each patient) was constructed with macular oedema (Clinical Standard) as the dependent variable, and as independent variables the central foveal thickness and the presence of intraretinal fluid. The goodness-of-fit of this model was assessed with the likelihood ratio test. The prognostic probabilities of this multivariate model and their AUC were calculated. The optimal point for the probabilities was determined [that which minimized the square root of (1sensitivity $\left.)^{2}+(1 \text {-specificity })^{2}\right]$ and non-linear equations were used to determine which values of foveal thickness presented a prognostic probability above the optimal point, distinguishing between the presence or absence of intraretinal fluid. Finally, calculations were made of the sensitivity, specificity, and the positive (PLR) and negative (NLR) likelihood ratios. To validate the model, we performed 1,000 bootstrapping samples to calculate: sensitivity, specificity, PLR, NLR and AUC (El Maaroufi et al., 2015). The analyses were all done with a significance of 5\% and the confidence interval (CI) was calculated for each relevant parameter. The calculations were done with IBM SPSS Statistics 19 and R 2.13.2.

\section{Ethical considerations}

The study was approved by the Ethics Committee of Elche Hospital and all the participants gave written informed consent (final approval date: February 24, 2014). All the personal information 
98

99

100

101

102

103

104

105

106

107

108

109

110

111

112

113

114

115

116

117

118

was deleted during the statistical analysis process. The study complies with the Declaration of Helsinki.

\section{RESULTS}

Of the 140 patients (280 eyes) seen during the study period, 3 eyes were excluded (1, vitreomacular traction syndrome; 1, macular degeneration; 1, epiretinal membrane). Of the remaining 277 eyes, 37 had macular oedema (13.36\%, 95\% CI: 9.35-17.36\%). The mean central foveal thickness was $270.4 \mu \mathrm{m}$ and $17.3 \%$ of the patients had intraretinal fluid according to the OCT. These values and the other descriptive characteristics can be seen in Table 1.

The logistic regression model was highly significant $\left(\mathrm{X}^{2}=141.5, \mathrm{p}<0.001\right)$ and gave an AUC of 0.88 (95\% CI: $0.82-0.95, \mathrm{p}<0.001)$ (Fig. 2). The equation for the prognostic probabilities can be found in Other S1. The cut points of central foveal thickness according to the presence or absence of intraretinal fluid are shown in Fig. 3. This figure shows that if the patient has intraretinal fluid, the test will be positive if the foveal thickness is $\geq 90 \mu \mathrm{m}$, whereas if there is no intraretinal fluid the cut point is $310 \mu \mathrm{m}$. This diagnostic test had the following clinical parameters: sensitivity, 0.83 (95\% CI: 0.69-0.92); specificity, 0.89 (95\% CI: 0.84-0.92); PLR, 7.34 (95\% CI: 5.00-10.78); and NLR, 0.19 (95\% CI: 0.10-0.36). The validation parameters using the bootstrapping methodology were: sensitivity, 0.83 (95\% CI: 0.71-0.93), specificity, 0.89 (95\% CI: 0.85-0.93); PLR, 7.28 (95\% CI: 5.18-11.19); NLR, 0.19 (95\% CI: 0.09-0.33); AUC, 0.89 (95\% CI: 0.80-0.94). 


\section{Summary}

121 This study determined cut points for foveal thickness taking into account the presence of

122 intraretinal fluid. In addition, the joint evaluation of these two parameters gave a high

123 discriminating power to differentiate between patients who really have macular oedema and

124 those who do not.

\section{5}

126

127

128

129

130

131

133

\section{Strengths and limitations of this study}

A literature search failed to detect any studies that evaluated jointly the two parameters analysed here (foveal thickness and intraretinal fluid) to detect diabetic macular oedema. Accordingly, our results are novel. The statistical power with the sample used was nearly $100 \%$ and the discrimination of the mathematical model was very high (AUC $>0.85)$. Finally, the OCT validated in this study is very simple to use, as it automatically focuses on the retina and does all the calculations; the user only has to look at them and make a clinical decision.

We attempted to minimise selection bias by using a sample obtained via a random design. Concerning information bias, all the variables were collected by expert ophthalmologists.

\section{Comparison with the existing literature}

In 2015 Virgili et al. published a meta-analysis analysing the discriminatory power of foveal thickness to diagnose diabetic macular oedema (Virgili et al., 2015). Calculation of the summary parameters in this meta-analysis was: sensitivity, 0.81; specificity, 0.85; PLR, 5.4; NLR, 0.22. With these parameters, we can calculate the summary distance on the ROC curve from the optimal cut point of foveal thickness to the left top vertex (sensitivity $=1$ and specificity $=1)$, 
140 obtaining a value of 0.2421 . Our study, though, gave a distance of just 0.2025 . In other words,

141 the discriminating power of our model is greater than that of the other studies; therefore, adding

142 the presence of intraretinal fluid improves the ability to detect diabetic macular oedema.

\section{Implications for clinical practice and research}

144 Analysis of our results and their comparison with other studies shows that the presence of

145 intraretinal fluid should definitely be taken into account when diagnosing macular oedema.

146 Moreover, the diagnostic test designed here does not just determine one single cut point, but

147 rather it constructs intervals of foveal thickness depending on the presence of intraretinal fluid.

148 Given that we have been unable to find any other studies that analysed jointly foveal

149 thickness and the presence of intraretinal fluid, we encourage others to determine whether these

150 results hold true in other populations with a different prevalence of macular oedema. If this is

151 found to be the case, we shall then have a more precise screening tool for macular oedema than

152 currently used (just foveal thickness).

Combining the presence of intraretinal fluid with central foveal thickness provides a tool to

156 discriminate precisely between diabetic patients with and without macular oedema. Furthermore,

157 given that the OCT used in this study is very simple to use and to interpret, it could become a

158 screening tool in primary healthcare. Finally, the very satisfactory results of this study suggest

159 that similar studies should also be done to provide greater scientific evidence for the use of

160 intraretinal fluid in the diagnosis of macular oedema. 
161

\section{ACKNOWLEDGMENTS}

163 The authors thank Maria Repice and Ian Johnstone for help with the English language version of 164 the text. 
165

166

167

168

169

170

171

172

173

174

175

176

177

178

179

180

181

182

183

184

\section{REFERENCES}

Aiello LM. 2003. Perspectives on diabetic retinopathy. American Journal of Ophthalmology 136:122-135. Review.

Aldington SJ, Kohner EM, Meuer S, Klein R, Sjølie AK. 1995. Methodology for retinal photography and assessment of diabetic retinopathy: the EURODIAB IDDM complications study. Diabetologia 38:437-444.

American Diabetes Association. 2014. Standards of medical care in diabetes--2014. Diabetes Care 37 Suppl 1:S14-80.

Baeza M, Orozco-Beltrán D, Gil-Guillen VF, Pedrera V, Ribera MC, Pertusa S, Merino J. 2009. Screening for sight threatening diabetic retinopathy using non-mydriatic retinal camera in a primary care setting: to dilate or not to dilate? International Journal of Clinical Practice 63:433438.

Baeza Diaz M, Gil Guillen V, Orozco Beltran D, Pedrera Carbonell V, Ribera Montes C, Pérez Pons I, Martínez Toldos J. 2004. Validez de la cámara no midriática en el cribado de la retinopatía diabética y análisis de indicadores de riesgo de retinopatía. Archivos de la Sociedad Española de Oftalmología 79: 433-442. 
186 Browning DJ, McOwen MD, Bowen RM Jr, O’Marah TL. 2004. Comparison of the clinical 187 diagnosis of diabetic macular edema with diagnosis by optical coherence tomography. 188 Ophthalmology 111:712-715.

Bursell SE, Cavallerano JD, Cavallerano AA, Clermont AC, Birkmire-Peters D, Aiello LP,

191

192

Aiello LM; Joslin Vision Network Research Team. 2001. Stereo nonmydriatic digital-video color retinal imaging compared with Early Treatment Diabetic Retinopathy Study seven standard field 35-mm stereo color photos for determining level of diabetic retinopathy. Ophthalmology 108: $572-585$.

El Maaroufi H, Goubard A, Redjoul R, Legrand P, Pautas C, Mikdame M, Doghmi K, Toma A, Maury S, Schwarzinger M, Cordonnier C. 2015. Risk factors and scoring system for predicting bacterial resistance to cefepime as used empirically in haematology wards. BioMed Research International 2015:945769.

Gómez-Ulla F, Fernandez MI, Gonzalez F, Rey P, Rodriguez M, Rodriguez-Cid MJ, Casanueva FF, Tome MA, Garcia-Tobio J, Gude F. 2002. Digital retinal images and teleophthalmology for detecting and grading diabetic retinopathy. Diabetes Care 25:1384-1389. 
Hanley JA, McNeil BJ. 1982. The meaning and use of the area under a receiver operating

206 characteristic (ROC) curve. Radiology 143:29-36.

Hee MR, Puliafito CA, Wong C, Duker JS, Reichel E, Rutledge B, Schuman JS, Swanson EA, Fujimoto JG. 1995. Quantitative assessment of macular edema with optical coherence tomography. Archives of Ophthalmology 113:1019-1029.

Hee MR, Puliafito CA, Duker JS, Reichel E, Coker JG, Wilkins JR, Schuman JS, Swanson EA,

213 Fujimoto JG. 1998. Topography of diabetic macular edema with optical coherence tomography.

214 Ophthalmology 105:360-370.

Herbert HM, Jordan K, Flanagan DW. 2003. Is screening with digital imaging using one retinal

217 view adequate? Eye 17:497-500. macular edema. Ophthalmoscopy versus photography--Early Treatment Diabetic Retinopathy

221 Study Report Number 5. The ETDRS Research Group. Ophthalmology 96: 746-750; discussion $750-751$. 
224 Koozekanani D, Roberts C, Katz SE, Herderick EE. 2000. Intersession repeatability of macular

225 thickness measurements with the Humphrey 2000 OCT. Investigative Ophthalmology \& Visual

226 Science 41:1486-1491.

228 No authors listed. 1985. Photocoagulation for diabetic macular edema. Early Treatment Diabetic

229 Retinopathy Study report number 1. Early Treatment Diabetic Retinopathy Study research group.

230 Archives of Ophthalmology 103:1796-1806.

232 No authors listed. 1987. Indications for photocoagulation treatment of diabetic retinopathy:

233 Diabetic Retinopathy Study Report no. 14. The Diabetic Retinopathy Study Research Group.

234 International Ophthalmology Clinics 27: 239-253.

236 Rudinsky CJ, Hinz BJ, Tennant MT, de Leon AR, Greve MD. 2002. High-resolution

237 stereoscopic digital fundus photography versus contact lens biomicroscopy for the detection of 238 clinically significant macular edema. Ophthalmology 109: 267-274.

240 Virgili G, Menchini F, Casazza G, Hogg R, Das RR, Wang X, Michelessi M. 2015. Optical

241 coherence tomography (OCT) for detection of macular oedema in patients with diabetic

242 retinopathy. Cochrane Database of Systematic Reviews 1:CD008081. 
244 World Health Organization. 2002. The World Health Report. Available at

245 http://www.who.int/whr/en (accessed April 2015). 


\section{Table $\mathbf{1}$ (on next page)}

Descriptive characteristics of the eyes of the diabetic patients studied.

Abbreviations: $B M I$, body mass index. $n(\%)$, absolute frequency (relative frequency); $x \pm s$, mean \pm standard deviation. 


\begin{tabular}{|l|c|}
\hline Variable & $\begin{array}{c}\text { Total }(\mathrm{n}=277) \\
\mathrm{n}(\%) / \mathrm{x} \pm \mathrm{S}\end{array}$ \\
\hline Male gender & $162(58.5)$ \\
\hline Type 2 diabetes mellitus & $249(89.9)$ \\
\hline Insulin use & $125(45.1)$ \\
\hline Vascular disease & $46(16.6)$ \\
\hline Stroke & $6(2.2)$ \\
\hline Coronary heart disease & $42(15.2)$ \\
\hline Hypertension & $137(49.5)$ \\
\hline Dyslipidaemia & $141(50.9)$ \\
\hline Smoking & $49(17.7)$ \\
\hline Intraretinal liquid & $48(17.3)$ \\
\hline Foveal thickness $(\mu \mathrm{m})$ & $270.4 \pm 45.1$ \\
\hline Age (years) & $61.6 \pm 13.0$ \\
\hline Years since diabetes diagnosis & $14.1 \pm 10.8$ \\
\hline BMI (kg/m $\left.{ }^{2}\right)$ & $28.8 \pm 4.9$ \\
\hline HbA1c $(\%)$ & $7.5 \pm 1.7$ \\
\hline Visual acuity & $0.85 \pm 0.20$ \\
\hline
\end{tabular}




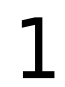

Screenshot of the retinal map analysis.

The presence of intraretinal fluid is seen in the upper left image (B-scan). Both the fundus image and the central foveal thickness are shown in the upper right image. The copyright holder (Topcon Corporation ${ }^{\circledR}$ ) has approved the utilization of this figure.

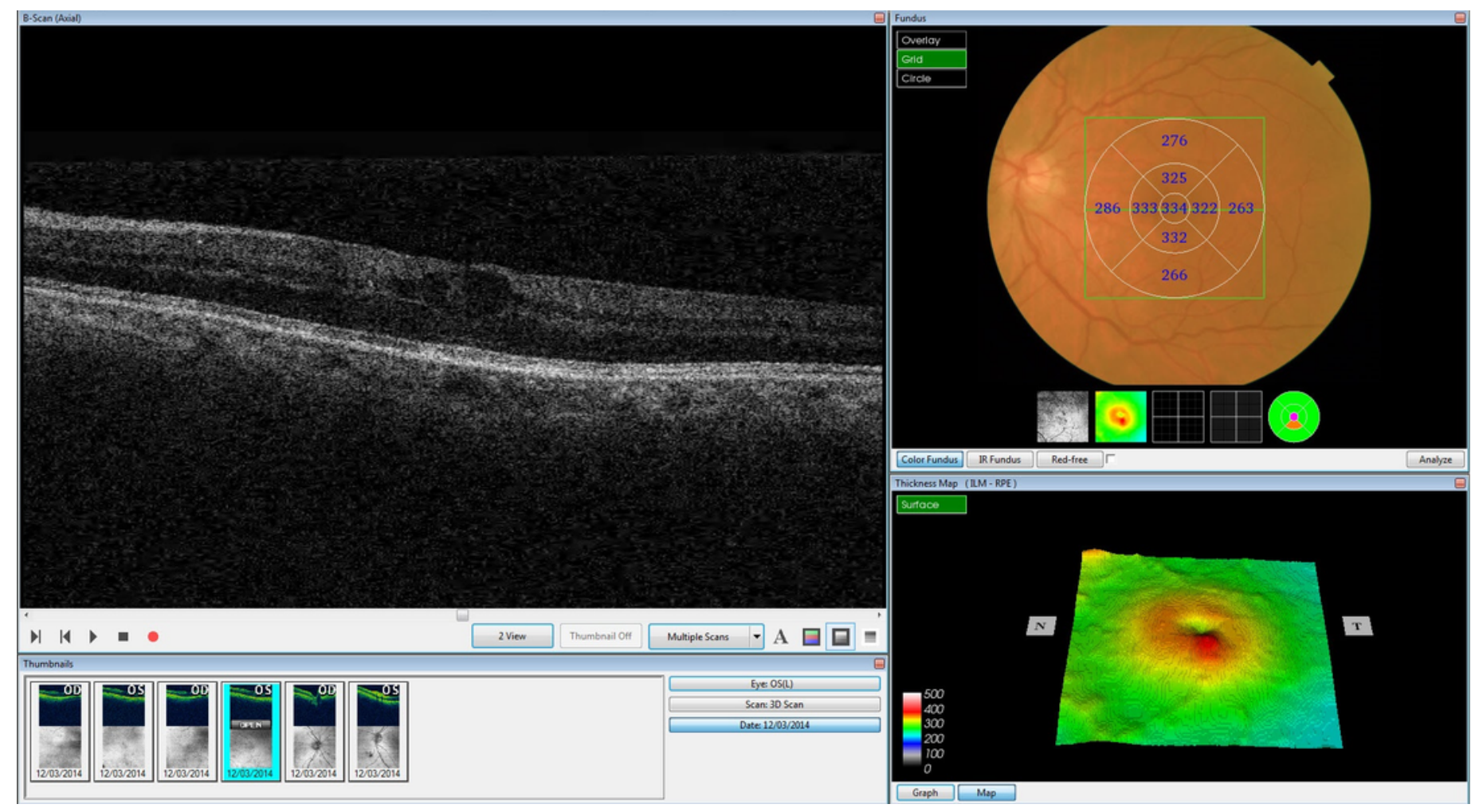


2

ROC curve of the prognostic probabilities of the multivariate model constructed.

AUC, area under the ROC curve; $\mathrm{Cl}$, confidence interval.

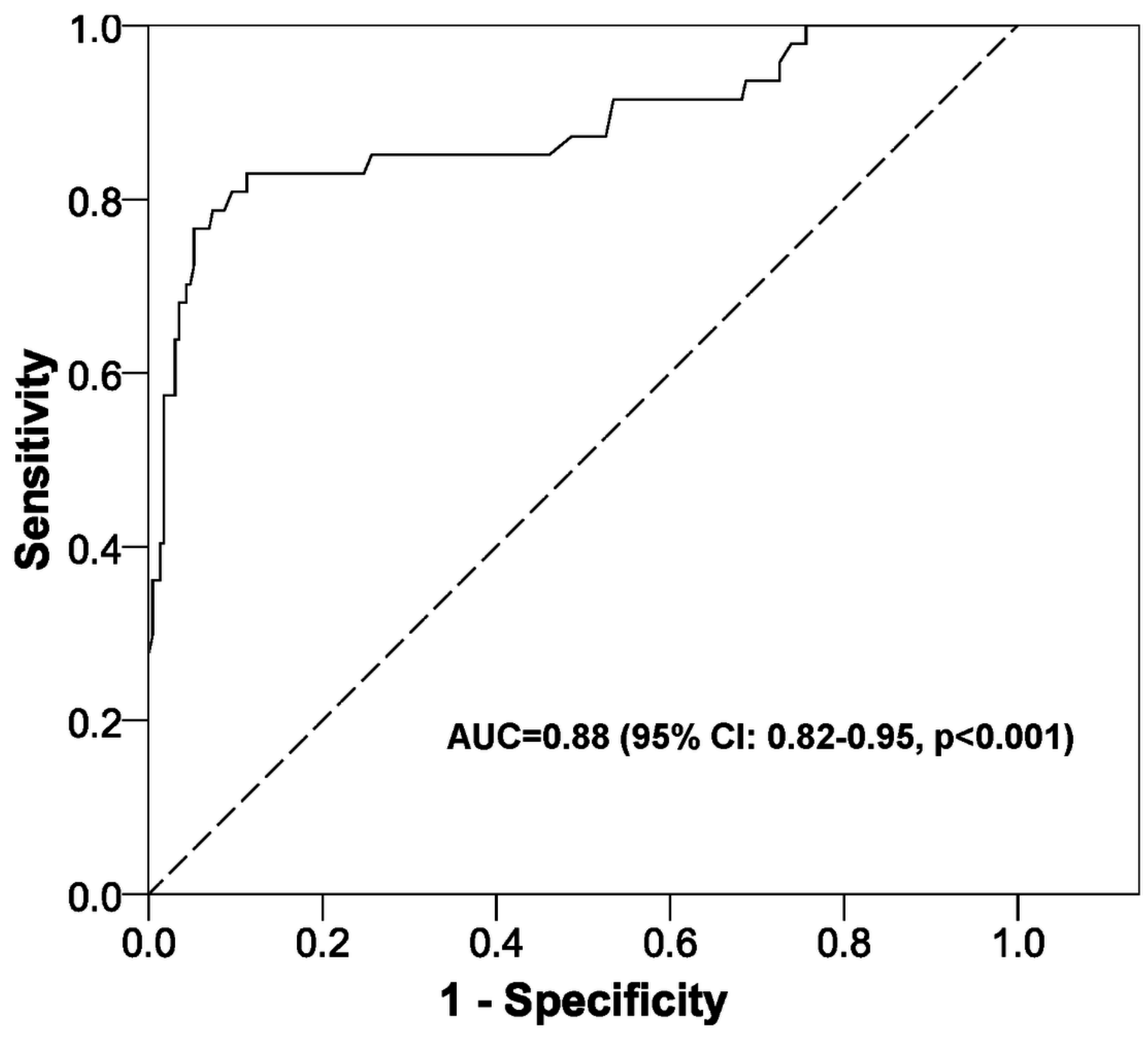




\section{3}

Cut points obtained for the diagnosis of diabetic macular oedema according to the presence or absence of intraretinal fluid.

\section{With intraretinal liquid}

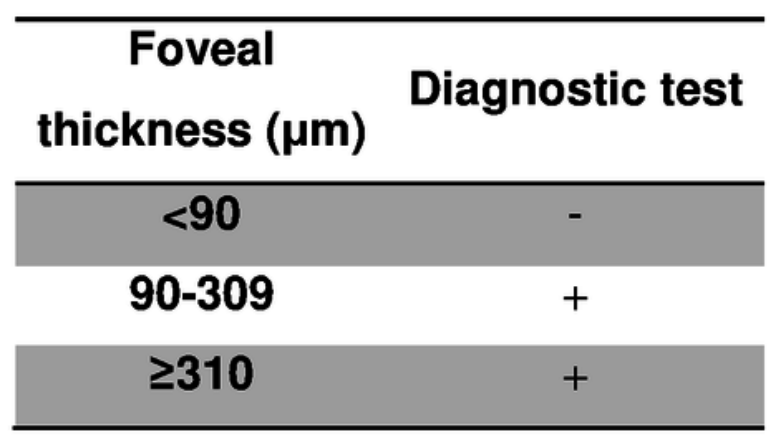

\section{Without intraretinal liquid}
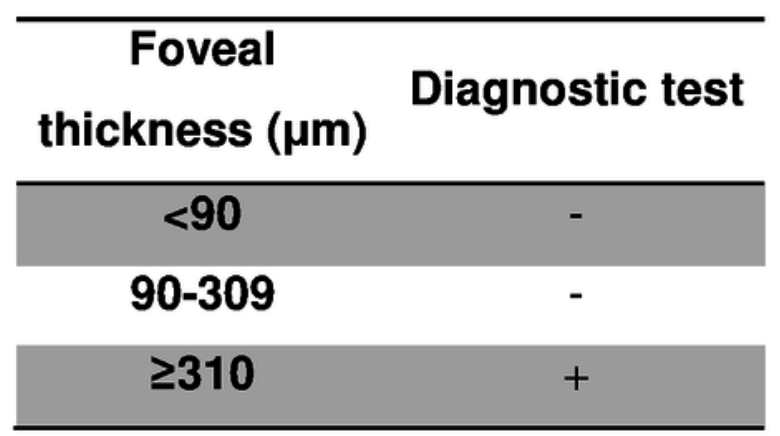